\title{
Comments on "The Findings and Policy Implications of the GAO Report and the Urban Institute Hiring Audit" by Michael Fix
}

Vernon M. Briggs, Jr.

Cornell University

Michael Fix begins with a review of the circumstances that led to the issuance by the U.S. General Accounting Office (GAO) of its congressionally mandate study of the implementation of the employer sanctions provisions of the Immigration Reform and Control Act of 1986 (IRCA). I would only take exception with one passing remark in this section. It is the use of the word "appease" in his mention that IRCA provided $\$ 4$ billion of federal funds "to appease states that feared that their services would be overrun by legalized aliens." Immigration policy has been held by the Supreme Court since 1892 (Elkie v. United States) to be solely the responsibility of the federal government. The full impact of the consequences of immigration policy-making, however, is played out in the cities and states where the immigrants actually live and work. Given that the legalization procedures involved at least 2.2 million persons (plus several million more illegal immigrants who did not apply or who were found not to be eligible for the amnesty) and that the full effects of the total number of additional family members of amnesty recipients who may eventually have their status adjusted is still unknown, the concerns of local and state governments over the derivative financial costs involved are very legitimate. Indeed, I have long believed that the federal government - as a matter of practice-should provide full funding to communities that are financially impacted by immigration just as it once did for local communities that were adversely impacted by the employment effects associated with the placement of national defense installations around the country. If the federal government were obligated to assume these financial costs, policy-makers might be less mesmerized by the alleged benefits and act more responsibly if they also had to embrace considerations of the actual costs of their decisions.

Turning to the thrust of Fix's article, he did have access to the critical memo from Eleanor Chelimsky that was unavailable to me at the time I prepared my review. The charge by Chelimsky that the GAO report may 
have overstated any adverse effects of IRCA (because it did not establish a baseline in order to distinguish what degree of discrimination existed in the labor market prior to IRCA) is a very serious concern. Indeed, to a methodological purist of the field of public policy evaluation, this omission would be considered a fatal flaw. The absence of a baseline, renders the precise numerical estimates of discrimination, that the report attributed to IRCA, suspect. Aside from this concern, it is still not possible to read the GAO report and fail to conclude that IRCA did cause new behavior responses by some employers. Whether by accident or by malevolence, these responses had adverse employment consequences-especially to persons of Hispanic origin. It is impossible to determine the exact magnitude of these new burdens. I also agree with Fix's observation that it is more likely that employers overstated their compliance practices in their responses to the employer survey rather than to have exaggerated their failures to comply. Hence, as stated in my article, I concur that some policy changes are required.

The preponderance of Fix's paper pertains to the "hiring audit" done by the Urban Institute and of which he was, at least partially, involved. He frankly and candidly states that the hiring audit confirmed the existence of disparate treatment against Hispanics, but "it did not link differential treatment to IRCA." It showed only that Hispanics "fared worse in terms of outcomes" which lead him to conclude that there appears to be significant labor market discrimination against Hispanics. Indeed, he says that Hispanic labor market experiences "may be more analogous to that of blacks." No one familiar with the vast literature on employment discrimination will contest the fact that there has been discrimination against Hispanics in the labor market nor that there is still discrimination. I do not know of any comparative studies, however, that show discrimination against Hispanics to be near that which confronts blacks. But, if the hiring audit did not mean to imply at least some link between IRCA's sanctions and the discriminatory outcomes it measured, then what was the purpose of including the findings of the hiring audit in a study whose only purpose was to detect the effects of the sanctions on employer conduct? I do not want to defend the findings of the hiring audit but I think Fix may have conceded too much in his remarks.

One serious problem with interpreting the findings of the audit is that it does not reveal anything about the characteristics of the employers. Were they all non-Hispanic whites? Were some black? Were some Hispanic? Why did 11 percent of the results of the non-Hispanic whites encounter unfavorable treatment? This aspect of the GAO study raises more questions than it answers. This is not meant to belittle GAO's work. Instead, as I suggested in my article, the findings have reopened the Pandora's Box pertaining to the entire subject of the magnitude and dimension of labor market discrim- 
ination in the United States. The Federal government's interest in this vital question has been downplayed or even suppressed since the advent of the Reagan-Bush Administration. If the GAO report helps to rekindle an active concern in the importance of equal employment opportunity policies, it will have made a major contribution to the nation's long-term welfare.

IRCA should not be made the scapegoat in this issue. I would submit that the economic advancement of minority group citizens requires that a much stronger employer sanctions program be enacted than currently exists. I agree with Fix that it is imperative that effects of employer sanctions be continually monitored. We disagree that future research might still provide a reason to sunset employer sanctions; I do not see any evidence to suggest that this is a conceivable policy outcome. I do see the necessity to make employer sanctions stronger (by squarely addressing the issue of worker identification, reducing the number of acceptable documents and adding financial penalties on illegal immigrants who are found to be employed).

As for the issue of whether the "testers" used in the hiring audit were actually indistinguishable to employers, I cannot resolve that methodological debate. It seems that the Urban Institute officials thought they were indistinguishable; Peter Skerry said they were not; and the GAO was uncertain since the report makes it clear that there is not any way to know exactly how employers actually perceived interviewees. 